\title{
Metabolism of Peripheral Nerve Myelin in
}

\section{Experimental Diabetes}

\author{
Norton Sprttz, Harbhajan Singh, and Barbara Marinan \\ From the Lipid Metabolism Laboratory, New York Veterans Administration \\ Hospital, the Department of Medicine, New York University School of \\ Medicine, and the Department of Biochemistry, Brookdale Dental \\ Center, College of Dentistry, New York University, New York 10010
}

A B S T R A C T Previous in vitro studies of the metabolism of the peripheral nerve have been based on incorporation of radioactive precursor into components isolated from whole nerve. In this study we have determined incorporation specifically into myelin components of peripheral nerve by isolating myelin after incubating whole nerves with lipid or protein precursors and by determining the specific activity of the components of that membrane. The effect of diabetes on such incorporation was also studied.

In the rat, in vitro incorporation of $\mathrm{DL}-\left[1-{ }^{14} \mathrm{C}\right]$ leucine into protein components of myelin was decreased by $30-88 \%$ in diabetic animals as compared to controls. The major polypeptide constituent of rat sciatic nerve myelin ( $m o l$ wt 28,000 ; $58.5 \%$ of total mass of proteins) was not labeled in either the diabetic or the control group. In diabetes incorporation rate into a polypeptide of mol wt 23,000 , which constitutes $21 \%$ of total mass, was approximately one half that of controls. In polypeptides of mol wt $38,000-49,000$, which are heavily labeled in normal animals, but constitute only about $5 \%$ of total mass of proteins, depression of incorporation was even more marked in the diabetics. While these marked differences in incorporation between diabetic and control animals were observed, the amount of protein and its distribution among the constituent polypeptides was the same in both groups.

In young rats made diabetic with streptozotocin and young rabbits made diabetic with alloxan, there was a lower rate of incorporation of the lipid precursors, $\left[1-{ }^{14} \mathrm{C}\right]$ sodium acetate or $\left[{ }^{3} \mathrm{H}\right]$ water, into myelin components. In older animals of both species incorporation in the controls was considerably lower than in the

Published previously, in part, in abstract form (1).

Received for publication 22 April 1974 and in revised form 9 January 1975. young animals, and the effect of diabetes was no longer apparent.

In nondiabetic animals, the in vitro addition of insulin $\left(10^{-7} \mathrm{M}\right)$ stimulated incorporation of $\mathrm{DL}-\left[1-{ }^{14} \mathrm{C}\right]$ leucine into myelin proteins 1.6-3.1 times that of controls. This stimulation by insulin in vitro was not seen in diabetic animals. In animals in which diabetes had spontaneously recovered, however, incorporation rate in the in vitro experiments approached that of controls and were significantly above that in animals whose diabetes persisted.

Since myelin is the plasma membrane of the Schwann cell, these studies provide evidence that the Schwann cell is affected by insulin and that some aspects of the metabolism of myelin are altered in insulin-deficient states.

\section{INTRODUCTION}

Studies of the metabolism of peripheral nerves from insulin-deficient (diabetic) animals, as well as investigations designed to show the effect of insulin on the peripheral nerve, have been carried out by several investigators $(2-6)$. These studies suggest that there is a decrease in some lipids in nerves from experimentally diabetic animals (4), and that incorporation of isotopic precursors into nerve lipid and carbon dioxide is variably decreased in experimental diabetes and is stimulated by insulin. These studies do not, however, provide information about the effects of diabetes on the chemistry or metabolism of myelin per se, since in all instances whole nerve was studied. In these investigations, large amounts of precursor were incorporated into cholesterol esters and di- and triglycerides. Because these lipids are not found in purified myelin, these results indicate that components of nerve uninvolved with myelin synthesis were responsible, at least in part, for the reported find- 
ings. The affected cells could include fat cells, fibroblasts, and other insulin-sensitive cells in whole nerve, rather than the Schwann cells that elaborate myelin.

The present investigation was designed to overcome this problem and to study the effect of experimental diabetes on the metabolism of peripheral nerve myelin components. A modification of the method of Rawlins and Smith (7) was utilized to study, in vitro, the incorporation of lipid and protein precursors into myelin. This report describes the effect of experimental diabetes on $(a)$ the incorporation of $\mathrm{DL}-\left[1-{ }^{14} \mathrm{C}\right]$ leucine into protein components of rat sciatic nerve myelin and the distribution of radioactivity among the polypeptides separated by polyacrylamide gel electrophoresis, $(b)$ the incorporation of $\left[1-{ }^{14} \mathrm{C}\right]$ sodium acetate and $\left[{ }^{3} \mathrm{H}\right]$ water into lipid components of rat and rabbit sciatic nerve myelin, and (c) effects of insulin, in vitro, on incorporation of $\mathrm{DL}-\left[1-{ }^{14} \mathrm{C}\right]$ leucine into myelin proteins of control and diabetic animals.

These studies indicate that in insulin-deficient animals the incorporation of myelin into both lipids and protein components is decreased. Because myelin is an extension of the plasma membrane of the Schwann cell, it can be concluded from these studies that Schwann cell is insulin sensitive. This conclusion is further supported by the finding that in nondiabetic animals insulin in vitro stimulates incorporation of $\mathrm{DL}-\left[1-{ }^{14} \mathrm{C}\right]$ leucine into myelin proteins, indicating that insulin plays a role in the metabolic activity of this membrane and of its parent cell, the Schwann cell.

\section{METHODS}

Materials. Male albino rats and New Zealand white rabbits were obtained from Zartman Farms, Douglassville, $\mathrm{Pa}$. Radioisotopes were obtained from New England $\mathrm{Nu}-$ clear, Boston, Mass. Specific activity was $2.0 \mathrm{mCi} / \mathrm{mmol}$ for $\left[1-{ }^{14} \mathrm{C}\right]$ sodium acetate, $1.0 \mathrm{Ci} / \mathrm{g}$ for $\left[{ }^{3} \mathrm{H}\right]$ water, and $5-16$ $\mathrm{mCi} / \mathrm{mmol}$ for $\mathrm{DL}-\left[1-{ }^{14} \mathrm{C}\right]$ leucine. In studies of leucine incorporation into individual polypeptide components of myelin, $\mathrm{DL}-\left[1-{ }^{14} \mathrm{C}\right]$ leucine of specific activity, $58 \mathrm{mCi} / \mathrm{mmol}$ obtained from Amersham/Searle Corp., Arlington Heights, IIl., was used. Glucagon-free insulin $(25.4 \mathrm{IU} / \mathrm{mg})$ was obtained from Lilly Research Laboratories, Indianapolis, Ind. Streptozotocin was obtained from the Upjohn Company through the courtesy of Dr. G. C. Gerritsen.

Production of diabetes. Diabetes was produced in the rats by use of streptozotocin ( $120 \mathrm{mg} / \mathrm{kg}$ given i.p.) when they were 4-wk old. Glycosuria was evident within 1 day, and rats were considered diabetic only when glycosuria was present at the time of sacrifice. Blood sugar determined by a Technicon Autoanalyzer (Technicon Instruments Corp., Tarrytown, N. Y.) was between 200 and $300 \mathrm{mg} / 100 \mathrm{ml}$. Diabetic rats at the time of sacrifice were $80 \%$ of the weight of their birth date controls. Rabbits were given alloxan ( $175 \mathrm{mg} / \mathrm{kg}$ i.v.) when they were 8 -wk old and were then maintained on 5-7 IU of protamine zinc insulin given each day. Glycosuria was always present, and blood sugars varied between 500 and $640 \mathrm{mg} / 100 \mathrm{ml}$. In both 4 and 8-mo-old animals, body weight was comparable in the diabetic and control rabbits.
In vitro incubations. In all experiments, food was withheld the previous evening, and the animals were killed in the morning; the rats were killed by cervical dislocation and the rabbits by an i.v. injection of barbiturate. Nerve segments were removed from their origin at the lumbar spine to the knee. In rats, each nerve was approximately $3.0-4.5 \mathrm{~cm}$ in length and weighed $30-60 \mathrm{mg}$; rabbit nerve was $6.5-8.5 \mathrm{~cm}$ in length and weighed $200-350 \mathrm{mg}$. Both nerves from a single animal were used in each incubation in the studies in rabbits, and nerves from 4 to 6 animals were pooled for the experiments on rats.

Nerves were cut into short segments approximately 1.0 $\mathrm{cm}$ in length and were incubated in $10 \mathrm{ml}$ of Krebs-Ringer bicarbonate buffer saturated with $95 \% \quad \mathrm{O}_{2}-5 \% \quad \mathrm{CO}_{2}$ as gas phase containing glucose at a concentration of $1.0 \mathrm{mg} / \mathrm{ml}$.

After preincubation for $30 \mathrm{~min}$, an appropriate radioactive precursor was added at a final concentration of $30 \mu \mathrm{Ci} / \mathrm{ml}$ for $\left[1-{ }^{14} \mathrm{C}\right]$ sodium acetate, $50 \mathrm{mCi} / \mathrm{ml}$ for $\left[{ }^{3} \mathrm{H}\right]$ water, and $50 \mu \mathrm{Ci} / \mathrm{ml}$ for $\mathrm{DL}-\left[1-^{14} \mathrm{C}\right]$ leucine. Cycloheximide $\left(10^{-3} \mathrm{M}\right)$, chloramphenicol $\left(10^{-3} \mathrm{M}\right)$, or insulin $\left(10^{-7} \mathrm{M}\right)$ were added at the beginning of incubation as indicated. The incubation was continued further for $60 \mathrm{~min}$. At the end of incubation, the mixture was frozen in dry-ice-acetone to terminate the reaction. After $15 \mathrm{~min}$, the tissue was thawed, and myelin was prepared as follows.

Isolation of myelin. The myelin was isolated by a modification of the method of Autilio, Norton, and Terry (8), which we have utilized previously for isolation of myelin from mouse brain (9) and human peripheral nerve (10), using a Beckman L2-65B preparative ultracentrifuge (Beckman Instruments Inc., Fullerton, Calif.). This procedure involves the following steps. (a) Nerves from four-six rats or from one rabbit were homogenized in $15 \mathrm{ml}$ of $0.25 \mathrm{M}$ sucrose using a Virtis homogenizer (The Virtis Co., Inc., Gardiner, N. Y.) and layered over $0.88 \mathrm{M}$ sucrose in three $13-\mathrm{ml}$ tubes. The tubes were centrifuged at $75,000 \mathrm{~g}(25,000$ $\mathrm{rpm}$ ) for $30 \mathrm{~min}$ in a SW-40 Spinco swinging bucket rotor (Beckman Instruments, Inc., Spinco Div., Palo Alto, Calif.). (b) The myelin separating at interphase was collected and was diluted with water to give $0.25 \mathrm{M}$ solution of sucrose; this was layered over $0.88 \mathrm{M}$ sucrose and step ( $a$ ) was repeated. (c) Myelin separating at interphase was collected and suspended in distilled water and centrifuged for $20 \mathrm{~min}$ at $80,800 \mathrm{~g}(35,000 \mathrm{rpm})$ using a $50 \mathrm{Ti}$ angle rotor. (d) The supernate in step (c) was discarded, the myelin pellet was dispersed in water, and step (c) was repeated. $(e)$ The supernate in step $(d)$ was discarded, and the pellet was dispersed in $0.3 \mathrm{M}$ cesium chloride. The myelin equivalent to nerves from two rats or one rabbit was layered on each tube containing in order, from top down, $8 \mathrm{ml}$ of a continuous gradient of $0.3 \mathrm{M}$ cesium chloride increasing to $1.3 \mathrm{M}$ cesium chloride and finally $2.0 \mathrm{ml}$ of $1.3 \mathrm{M}$ cesium chloride. The tube was centrifuged for $60 \mathrm{~min}$ at $100,000 \mathrm{~g}$ $(29,000 \mathrm{rpm})$. In both control and diabetic animals a single compact white layer of myelin near the middle of the tube was present. This fraction was collected, diluted with distilled water, and centrifuged at 75,000 $g(25,000 \mathrm{rpm})$ for $20 \mathrm{~min}$ to obtain a well-packed pellet. The pellet was suspended in water, and portions of this suspension were used for analysis.

Purity of the finally isolated myelin was evaluated by the following criteria. (a) A single compact band of myelin floating at the same position in continuous gradient was obtained from both control and diabetic nerves from rat and rabbit; $(b)$ the preparations were completely soluble in chloroform, methanol $(2: 1)$; (c) chemical composition of isolated myelin was in the same range as described for 
myelin (10) and different from all other membranes (11); (d) microsomal membranes, the most likely contaminant, were isolated, and they remained in the $1.3 \mathrm{M}$ cesium chloride part of gradient and clearly separate from myelin; (e) by electron microscopic examination the absence of nerve trunks as well as other nonmembranous material was verified, and $(f)$ in rabbits, myelin was analyzed for $\mathrm{NADPH}$ cytochrome $c$ reductase activity, and specific activity of that enzyme in the myelin preparation was less than $10 \%$ of that in microsomes.

The composition of rabbit sciatic nerve myelin has been previously published (10). The rat sciatic nerve myelin contained (values are average of two determinations each on four different preparations) $22 \%$ protein (by weight based on dry weight) ; the lipid composition based on mol/100 mol of total lipid was: cholesterol, 37.1; total glycolipid, 21.8; total phospholipid, 41.1; phosphatidyl ethanolamine, 2.6 ; phosphatidal ethanolamine, 13.4; phosphatidyl choline, 12.2; phosphatidyl serine, 5.0, and sphingomyelin 8.0. The amount and composition of myelin was the same in diabetic and nondiabetic animals in both rat and rabbit for the duration of diabetes reported in these studies.

Extraction of lipids and specific activity determination. The lipids from aqueous myelin suspension were extracted essentially by the procedure of Folch, Lees, and Sloane Stanley (12). To $1.0 \mathrm{ml}$ of myelin suspension was added $20 \mathrm{ml}$ of chloroform: methanol (2:1), and a clear to faintly opalescent single-phase solution was obtained. This solution was washed with pure solvent "upper phase," and the lipid was recovered from the chloroform solution. Lipids for quantitative analysis were separated by two-dimensional thin-layer chromatography using the solvents described by Rouser, Kritchevsky, and Yamamoto (13), as used previously (9). Thin-layer chromatography was done on layers of silica gel $\mathrm{H}, 500 \mu \mathrm{m}$ thick and activated at $110^{\circ} \mathrm{C}$ for $1 \mathrm{~h}$. The chromatograms were developed in the first dimension with chloroform: methanol:28\% aqueous ammonia $(65: 35: 5)$, and the strip containing the lipid was sprayed with $12 \% \mathrm{HCl}$ by weight in methanol. This procedure hydrolyses the alkenyl linkages, so that the material isolated as lysophosphatidyl ethanolamine, after development in the second solvent, represents the original alk-1-enyl compounds (phosphatidal ethanolamine). After $5 \mathrm{~min}$ the $\mathrm{HCl}$ was removed under a stream of nitrogen, and the plate was then developed in the second dimension with chloroform: acetone: methanol: acetic acid: water, $(5: 2: 1$ : $1: 0.5)$. The lipids were visualized by brief exposure to iodine vapor, appropriate areas of plates were scraped, and the lipids were eluted with methanol. Phosphorus was determined on a portion by the procedure of Bartlett (14), and galactose was measured by the ferricyanide procedure (15). On another portion radioactivity was determined by liquid scintillation counting (see below).

Isolation of myelin proteins and determination of specific activity. To an ice-cold suspension of myelin in water was added an equal amount of ice-cold $10 \%$ trichloroacetic acid. The precipitate was centrifuged and washed twice with icecold $5 \%$ trichloroacetic acid $(3.0 \mathrm{ml})$. The precipitate was then extracted with methanol ( 3 times, $2 \mathrm{~min}$ ) and acetone ( 3 times, $2 \mathrm{ml}$ ) to remove the lipids. The insoluble protein precipitate was washed with $5 \%$ trichloroacetic acid (once with $1.0 \mathrm{ml}$ ). The residue obtained was dried under a stream of nitrogen, and to this was added $0.2 \mathrm{ml}$ of IN $\mathrm{NaOH}$ and made to a volume of $1.0 \mathrm{ml}$ with $1 \%$ sodium dodecyl sulfate. On a portion protein was determined by the procedure of Lowry, Rosebrough, Farr, and Randell (16), and on another portion radioactivity was measured by liquid scintillation counting.

Polyacrylamide gel electrophoresis and determination of radioactivity in gels. The protein isolated by the fractionation procedure described above, after final trichloroacetic acid wash, was dissolved in $2 \%$ sodium dodecyl sulfate to give a protein concentration of $2-5 \mathrm{mg} / \mathrm{ml}$. The polypeptide components were then separated by polyacrylamide gel electrophoresis. Gel electrophoresis in sodium dodecyl sulfate, staining, destaining, and scanning of gels has been described in detail in our recent publication (17). After scanning the gels stained with Coomassie Blue, the major peptides were marked by inserting a small wire in each band. This procedure established the position of each stained component, and its position could be readily determined in the slice. The gels were frozen at $-20^{\circ} \mathrm{C}$ and while frozen were cut transversely at $1-\mathrm{mm}$ intervals with a razor blade "stack". Each 1-mm slice was placed in a separate scintillation counting vial and digested with $0.2 \mathrm{ml}$ of $6 \%$ (wt/vol) hydrogen peroxide at $50^{\circ} \mathrm{C}$ for $16-18 \mathrm{~h}$. At the end of this interval gels were completely decolorized and dissolved, and radioactivity was determined by liquid scintillation counting as described below.

Radioactivity determination. Radioactivity was determined by using a Beckman Liquid Scintillation Spectrophotometer (Beckman Instruments Inc.) at an efficiency of ${ }^{78 \%}$ for ${ }^{14} \mathrm{C}$ and $41 \%$ for ${ }^{3} \mathrm{H}$, using calibrated ${ }^{14} \mathrm{C}$ and ${ }^{8} \mathrm{H}$ standards. The phosphor was $0.4 \%$ (wt/vol) 2,5-diphenyloxazole (PPO), $0.01 \%$ (wt/vol) of 1,4-bis-[2-4-(4-methyl5-phenyloxazoly1) ] benzene (dimethyl POPOP), 9.5\% (vol/ vol) of Bio-Solv BBS-3 (Beckman Instruments, Inc.) in toluene for aqueous protein samples. For lipid samples the phosphor was $0.4 \%$ (wt/vol) 2,5-diphenyloxazole (PPO), $0.005 \%$ (wt/vol), 1,4-bis-[2-(5-phenyloxazolyl)]benzene in toluene.

\section{RESULTS}

Characteristics of the in vitro incorporation system. Incorporation of $\mathrm{DL}-\left[1{ }^{14} \mathrm{C}\right]$ leucine into protein and $\left[{ }^{3} \mathrm{H}\right]$ water or $\left[1-{ }^{14} \mathrm{C}\right]$ sodium acetate into lipid components of the isolated myelin was linear with time for $120 \mathrm{~min}$, with an intercept on the time axis at $12 \mathrm{~min}$. For this reason the tissue was preincubated for $30 \mathrm{~min}$ after which first order kinetics were achieved with intercept at time zero. These findings are illustrated in Fig. 1 for nerves from nondiabetic 4-wk-old rats.

Cycloheximide $\left(10^{-3} \mathrm{M}\right)$ inhibited incorporation of labeled leucine into rat nerves by more than $90 \%$ while chloramphenicol $\left(10^{-s} \mathrm{M}\right)$ had little effect $(90 \%$ of control). A mixture of both inhibitors of protein synthesis produced inhibition comparable to that of cycloheximide alone.

Incorporation of $\mathrm{DL}-\left[1{ }^{1 "} \mathrm{C}\right]$ leucine into myelin proteins of sciatic nerves from diabetic and control rats. Incorporation of DL- $\left[1-{ }^{11} \mathrm{C}\right]$ leucine into myelin components was higher in younger as compared to older animals, and this was similar to that reported by others (7). For this reason, comparisons between diabetic and control animals were made in age-matched pairs. There was a total of eight experiments. As indicated in Fig. $2 a$, rats $6 \frac{1}{2}-17$-wk old were studied, the diabetes having been 


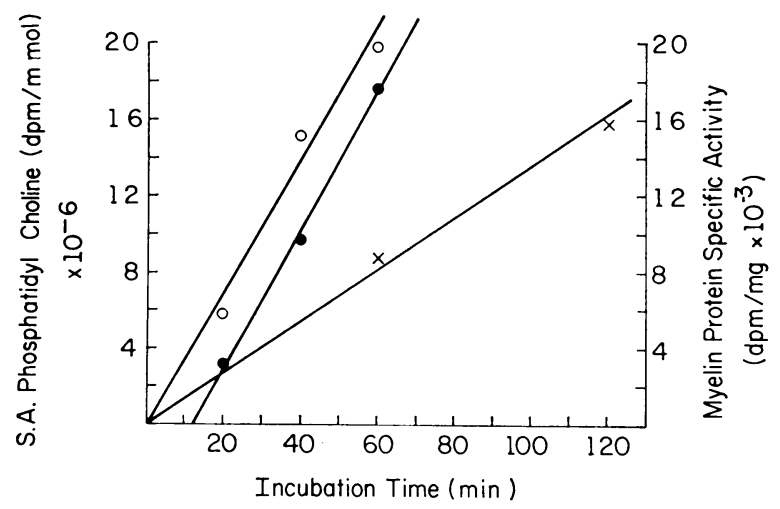

FIgURE 1 Time-course of incorporation of $\mathrm{DL}-\left[1{ }^{14} \mathrm{C}\right]$ leucine into proteins and $\left[1-{ }^{14} \mathrm{C}\right]$ sodium acetate into phosphatidyl choline of rat sciatic nerve myelin. Nerves from four to six rats (4-wk old) were incubated at $37^{\circ} \mathrm{C}$ in KrebsRinger bicarbonate buffer. Each point represents nerves pooled from four to six rats from a single lot. After preincubation for $30 \mathrm{~min}$, isotopic precursor $\left[1{ }^{14} \mathrm{C}\right]$ sodium acetate, $30 \mathrm{mCi} / \mathrm{ml}$, or $\mathrm{DL}-\left[1-{ }^{14} \mathrm{C}\right]$ leucine, $50 \mathrm{mCi} / \mathrm{ml}$ was added. At the end of the incubation reaction was stopped by freezing in dry-ice-acetone mixture, and myelin was prepared (see text) from nerves and specific activity of phosphatidyl choline and proteins was determined. $\mathrm{O}-\mathrm{O}$ is the incorporation into phosphatidyl choline, when nerves were preincubated. - is the incorporation into phosphatidyl choline without preincubation of nerves. $X-X$ is the incorporation into proteins after the nerves have been preincubated.

produced in all animals at age $4 \mathrm{wk}$. In two groups of younger animals, high levels of incorporation were seen in the control group. In all eight comparisons, using nerves from animals $6 \frac{1}{2}-17$-wk old, the diabetics showed lower incorporation ranging from 12 to $70 \%$ of their age-matched controls. The data of eight experiments of control and diabetic groups are pooled and presented in Fig. $2 b$. In rabbits, rate of incorporation of DL$\left[1-{ }^{14} \mathrm{C}\right]$ leucine into protein was too low for study.

The distribution of radioactivity among polypeptides of rat sciatic nerve myelin from two different preparations separated by polyacrylamide gel electrophoresis is shown in Fig. $3 a$ and $b$. The data are typical of five different paired experiments for control and diabetic groups. The pattern of polypeptide components stained with Coomassie Blue was the same in both control and diabetic groups and was similar to that previously reported (17).

In myelin from both diabetic and control animals, there was little or no incorporation of isotope into the major polypeptide component (mol wt 28,000) which constitutes $58.5 \%$ of the total mass (17). Incorporation into the second largest component (mol wt 23,000, 21\% of total mass) was approximately two times higher in the control group than in the diabetic group. The high molecular weight components ( $\mathrm{mol}$ wt 38,000-49,000; components in slice numbers $15-30$ ) were heavily labeled especially when related to the mass, and in this group of polypeptides incorporation in the diabetic animals was even more impaired.

Myelin prepared from incubations done in presence of cycloheximide and $\mathrm{DL}-\left[1-{ }^{14} \mathrm{C}\right]$ leucine was also analyzed by polyacrylamide gel electrophoresis (not shown). The pattern of radioactivity from these gels did not show any radioactive peaks, and in all the fractions a background count of 14-18 cpm was observed. These experiments indicated that all the radioactive peaks seen in Figure $3 a$ and $b$ are due to incorporation into protein components of myelin, rather than nonspecific adsorption of labeled amino acid.

Incorporation of labeled precursors into lipid components of rat and rabbit myelin. In the rat, incubation of sciatic nerve with either $\left[1{ }^{14} \mathrm{C}\right]$ sodium acetate or $\left[{ }^{3} \mathrm{H}\right]$ water led to sufficient labeling of myelin phosphatidyl choline, phosphatidyl ethanolamine, and phosphatidyl serine; sphingomyelin, phosphatidal ethanolamine, cerebrosides, and sulfatides were insufficiently labeled. In the present investigation, the acid labile nature of phosphatidal ethanolamine was exploited to separate it from phosphatidyl ethanolamine. The relative amount of phosphatidal ethanolamine and phosphatidyl ethanolamine was 85 and 15 respectively, in rat sciatic nerve myelin. Fig. $4 a$ shows incorporation of $\left[{ }^{3} \mathrm{H}\right]$ water into phosphatidyl choline in four experiments utilizing rats from 9-18-wk old in which diabetes had been produced at age $4 \mathrm{wk}$. The younger animals, both diabetic and control, had higher incorporation rates, and in each case, the diabetic was significantly lower. In Figure $4 b$, data in the diabetic groups are presented as the percent of the control for the three phospholipids
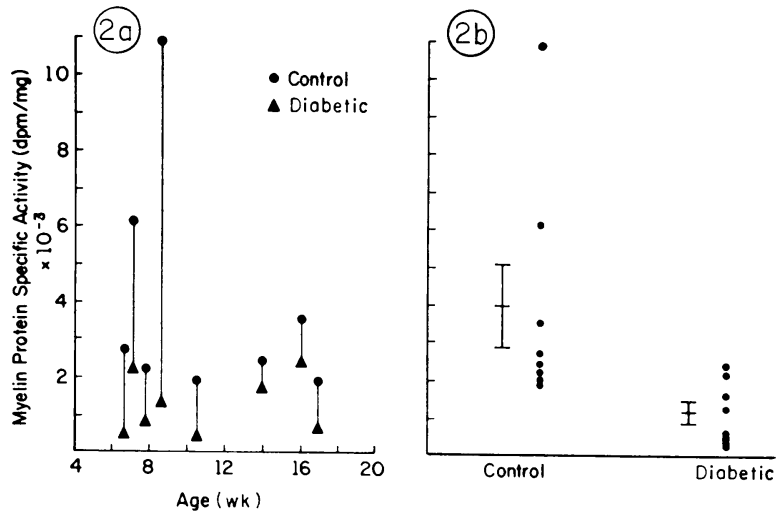

FIGURE 2 Incorporation of $\mathrm{DL}-\left[1-{ }^{11} \mathrm{C}\right]$ leucine into the proteins of rat sciatic nerve myelin in diabetic and control rats. The nerves were incubated for $60 \mathrm{~min}$. (a) The eight experiments are presented in relationship to the age of the rats. All animals were made diabetic at age $4 \mathrm{wk}$. (b) The data of Figure $2 a$ are pooled for the diabetic and control groups. In the vertical bar, data are expressed as Mean $\pm \mathrm{SE}$. 

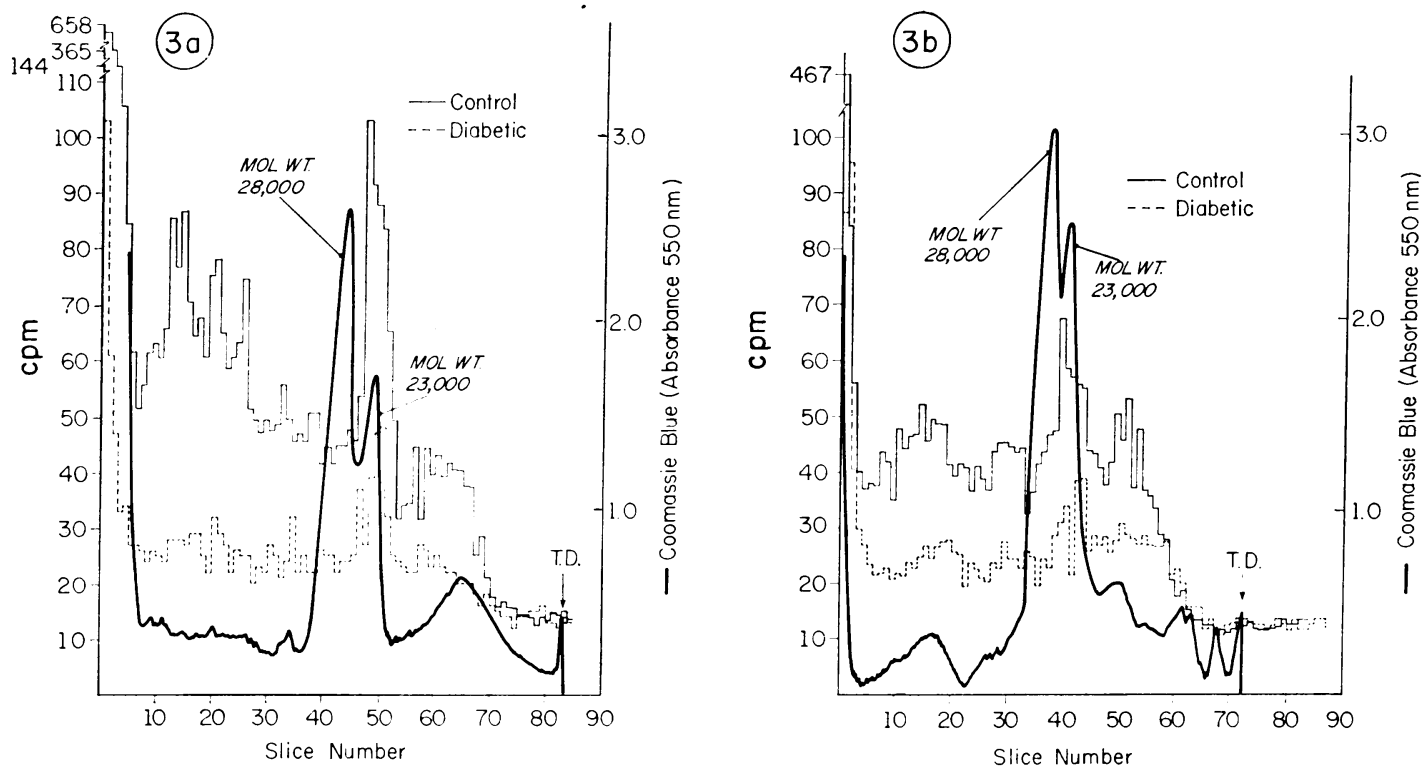

Figure 3 Polyacrylamide gel electrophoretic analysis of sciatic nerve myelin proteins from control and diabetic rats. The heavy line represents mass distribution by staining with Coomassie Blue (17) and is the same in diabetic and control animals. After scanning, the gels were sliced, digested with hydrogen peroxide, and counted (blocked traces). The data from two different preparations are presented in Figure $3 a$ and $b$. For each incubation nerves from three rats were used. On each gel the same amount of protein was applied. The rats were $7 \frac{1}{2}$-wk old and were made diabetic at age $4 \mathrm{wk}$. There were a total of five such experiments (methods are described in the text). India ink marks were inserted before fixation and staining shows the final position of bromophenol blue tracking dye (T.D.).

that were sufficiently labeled. It is evident that for most of these lipids in various age groups, incorporation in the diabetic nerves was considerably lower than that of the controls.
In the rabbit, all experiments were carried out with $\left[{ }^{3} \mathrm{H}\right]$ water, and sufficient incorporation was seen only in phosphatidyl choline. In these experiments right and left nerves from a single animal were pooled in each
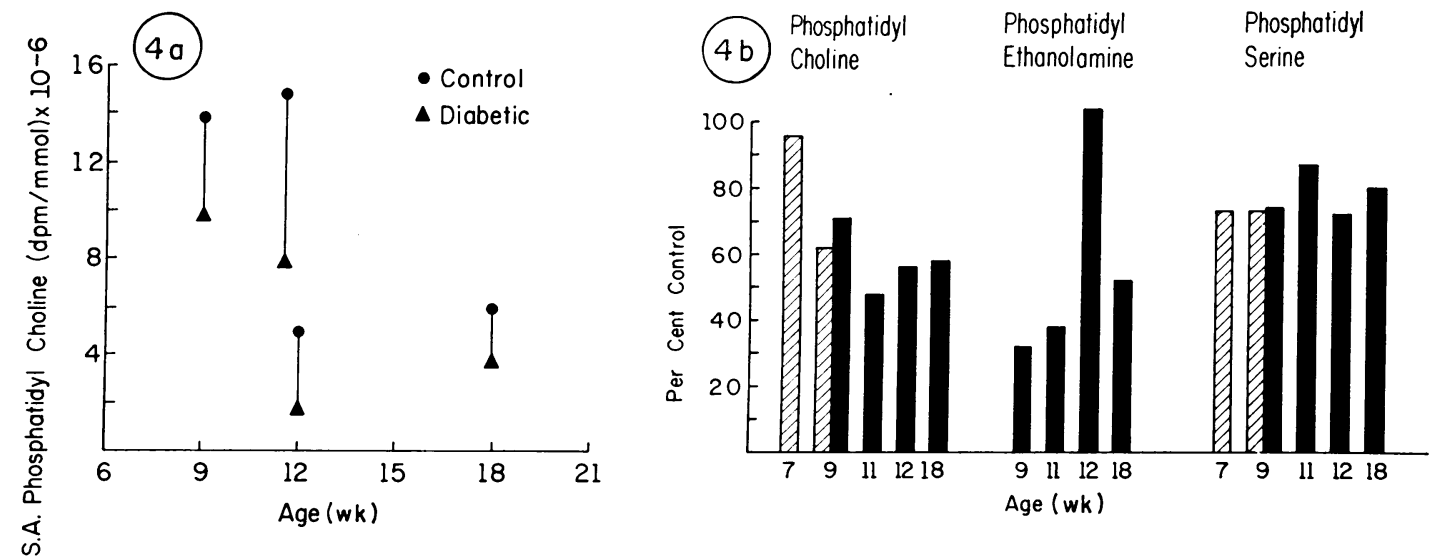

FIGURE 4 Incorporation of $\left[1-{ }^{14} \mathrm{C}\right]$ sodium acetate and $\left[{ }^{3} \mathrm{H}\right]$ water into lipids of control and diabetic rat sciatic nerve myelin. The nerves were incubated for $60 \mathrm{~min}$ after the addition of radioactive precursor $(4 a)$. Four experiments in which incorporation of $\left[{ }^{8} \mathrm{H}\right]$ water into phosphatidyl choline is presented in relationship to age of animals. The animals were made diabetic at age 4 wk $(4 b)$. Incorporation of $\left[1-{ }^{14} \mathrm{C}\right]$ sodium acetate (cross bars) and $\left[{ }^{3} \mathrm{H}\right]$ water (solid bars) into myelin phosphatidyl choline, phosphatidyl ethanolamine, and phosphatidyl serine in diabetic rats. The data are expressed for diabetics as percent of controls. 


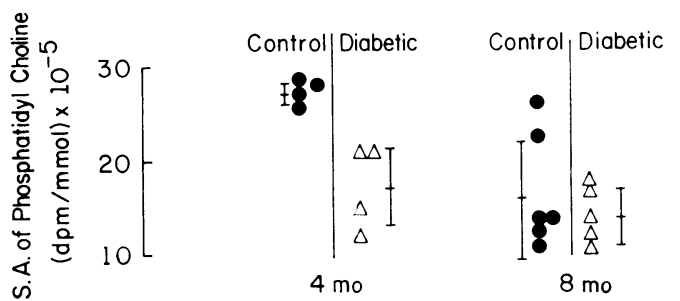

FIGURE 5 Incorporation of $\left[{ }^{3} \mathrm{H}\right]$ water into rabbit sciatic nerve myelin. The animals were 4- and 8-mo old and were made diabetic at age 2 mo. In each experiment the right and left nerve from one animal was incubated for $60 \mathrm{~min}$ after addition of radioactive precursor. Myelin was then isolated and specific activity of phosphatidyl choline determined.

incubation. As indicated in Fig. 5, incorporation was higher in 4-mo-old control animals than in the 8-mo-old group (sp act $2,780 \pm 145 \mathrm{dpm} / \mu \mathrm{mol}$ vs. $1,663 \pm 638 \mathrm{dpm} /$ $\mu \mathrm{mol} ; P<0.001)^{1}$. In the diabetic animals incorporation rate was significantly lower in the 4-mo-old animals (sp act $1,710 \pm 442 \mathrm{dpm} / \mu \mathrm{mol} ; P<0.001)^{1}$ compared to age-matched controls and was like that of 8 -mo-old diabetic and control animals.

Effects of insulin on incorporation of DL- $\left[1-{ }^{14} \mathrm{C}\right]$ leucine into rat sciatic nerve myelin. The results of six experiments in which insulin $\left(10^{-7} \mathrm{M}\right)$ was present in incubation medium containing $1.0-\mathrm{cm}$ segments of sciatic nerves from 4-wk-old rats are presented in Fig. $6 a$. Each pair of results (with and without insulin) are from the same pool of nerves. Specific activity of isolated proteins ranged from 1.6 to 3.1 times that of the controls with a mean of 2.2. Similar experiments with 7 -wk-old diabetic rats (diabetes was produced when animals were $4 \mathrm{wk}$ old) are presented in Fig. $6 \mathrm{~b}$. Although considerable variation was observed, stimulation by insulin, except in one experiment, could not be shown.

Incorporation of $\mathrm{DL}-\left[1-{ }^{14} \mathrm{C}\right]$ leucine into myelin from rats spontaneously recovered from diabetes. Several animals recovered from diabetes spontaneously, after being diabetic for 3 wk after receiving streptozotocin. In two experiments incorporation of $\mathrm{DL}-\left[1-{ }^{14} \mathrm{C}\right]$ leucine into sciatic nerve myelin protein of animals recovered spontaneously from diabetes was 63 and $90 \%$ of the controls in comparison to the diabetic animals which were 25 and $35 \%$ of the controls. In both experiments, spontaneously recovered animals had higher incorporation that the age-matched diabetic, but the incorporation was lower than in the controls.

\section{DISCUSSION}

In this study, we have provided two lines of evidence that the metabolism of some components of myelin are

\footnotetext{
${ }^{1}$ Values are the mean \pm SD of myelin phosphatidyl choline specific activity, disintegrations per minute per micromoles of phosphorus.
}

influenced by insulin: (a) there was decreased incorporation of isotopic precursors into myelin components by diabetic animals; $(b)$ the in vitro addition of insulin in control animals stimulated incorporation of leucine into myelin proteins.

We have not been able to show in vitro the stimulating effect of insulin on incorporation of leucine into nerves from diabetic animals, similar to that seen in nondiabetic controls. The reason for this is not known at present, but it is likely that, with prolonged insulin deficiency, enzymes necessary for the synthesis of myelin or specific receptors necessary for insulin are inactive
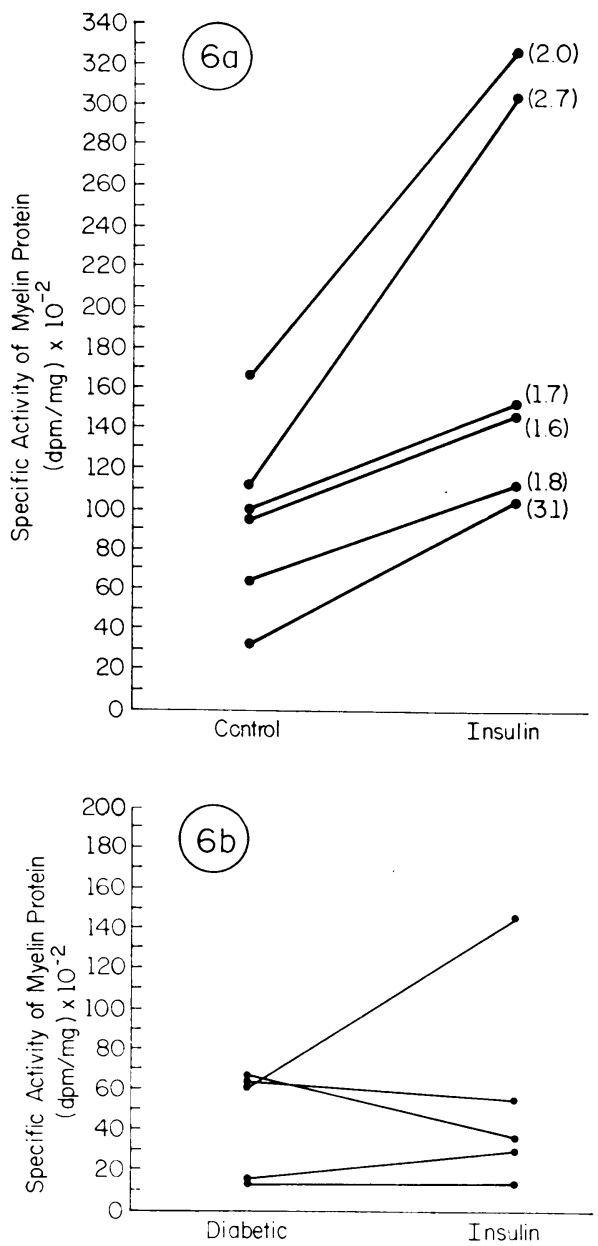

Figure 6 (a) Effect of addition of insulin $\left(10^{-7} \mathrm{M}\right)$ on in vitro incorporation of $\mathrm{DL}-\left[1-{ }^{14} \mathrm{C}\right]$ leucine into sciatic nerve myelin proteins. The nerve from 3-4-wk-old rats were incubated in Krebs-Ringer bicarbonate buffer containing insulin. The numbers in parentheses are the ratios of specific activity in myelin protein with insulin to those without insulin. (b) Five experiments showing the effect of addition of insulin $\left(10^{-7} \mathrm{M}\right)$ on in vitro incorporation of DL$\left[1-{ }^{14} \mathrm{C}\right]$ leucine into myelin from 7 -wk-old diabetic animals. The animals were made diabetic when they were 4-wk old. In each experiment nerves from two animals were pooled. 
or absent, and their activity is not replaced during in vitro incubations. Because the control animals in which insulin effect was demonstrable were 3 wk younger than the diabetics, an effect of age on insulin responsiveness can not be eliminated. Unfortunately, we were unable to produce diabetes early enough to permit comparable studies. The higher incorporation rates in spontaneously recovered diabetic animals as compared to age-matched animals with persistent diabetes do, however, show that the effect of insulin deficiency can in part be corrected by the availability of insulin in vivo.

As shown by other investigators (7), we found that incorporation of precursors into myelin components is a strongly age-related phenomenon, and only in younger animals with higher incorporation rates could the impairment in diabetes be demonstrated. It is important to note, however, that when lower rates of incorporation are present, as in the older control animals, comparable impairment in diabetes to that seen in young animals may not be detected in this system. For this reason, we can not eliminate the possibility that the defect seen in young diabetic animals persists with aging.

The interpretation of these data depend on several methodological considerations. Purity of the isolated myelin is supported by data that indicate that the isolated material had the compositional, electron micrographic, enzymatic, and solubility characteristics typical of myelin. In the studies on incorporation of precursors into proteins, complete removal of any adsorbed amino acid on protein requires special purification. The inhibition of incorporation of amino acid by cycloheximide, as well as the association of isotope in proteins separated by polyacrylamide gel electrophoresis (17), indicate that this was achieved.

Effects of the rate of incorporation in in vitro studies can not be equated with changes in in vivo synthesis. Differences in the rate of incorporation could reflect the effect of the specific activity of the precursor pool. This, however, is an unlikely explanation for our findings, since the specific activity of $\left[{ }^{3} \mathrm{H}\right]$ water should not be diluted by metabolic activity, or related to diabetes or insulin addition in in vitro system. The concentration of leucine in incubation medium was high (0.9$3.2 \mathrm{mM}$ ), and, especially after preincubation, it can be assumed that all pools of this amino acid would have equilibrated with the high concentration in the incubation media. Similarly, if the product pool (i.e., the total amount of myelin) were different between the diabetic and control animals, differences in specific activity would be seen, even at the same rates of precursor incorporation. This possibility is ruled out by our findings (1) that the amount of myelin, at least in younger animals, is the same in controls as in the diabetic rats and rabbits. The finding of marked differences in isotopic incorporation rates in the absence of changes in the total content of myelin suggests either that breakdown of myelin component is also impaired, resulting in slower turnover, or that the components in the membrane affected by insulin reflect only a small portion of the total pool in which metabolic activity is high. We have found, however, that in older rabbits (9-13-mo old) there is a decrease in myelin with prolonged diabetes. ${ }^{2}$

Qualitatively similar effects seen in rabbits that had received alloxan to those in rats receiving streptozotocin provide evidence against the possibility that our findings reflect an effect of the agent to induce diabetes rather than the insulin-deficient state itself. The evidence that the effects seen are due to the insulin-deficient state are further supported by the improvement seen in the incorporation rates in animals that recovered spontaneously from diabetes. Because the diabetic rabbits were maintained at the body weight of controls, the findings in the rabbit provide evidence at the lower rate of incorporation in diabetics is not the result of nutritional factors.

The possibility that insulin exerts its effect by increasing the transport of the precursor into the cell, rather than by direct stimulation of synthesis, cannot be rigorously excluded. This possibility seems unlikely in case of $\left[{ }^{3} \mathrm{H}\right]$ water but could explain the effects of insulin deficiency (in diabetic animals) and addition (in control animals) on the incorporation of leucine into myelin proteins. Further differences in the magnitude of effect of diabetes on the incorporation into different polypeptides of myelin suggest that insulin deficiency produces specific effects on myelin protein metabolism, which can not be explained by effects of insulin on transport of precursor into the cell alone.

The data concerning incorporation of isotopic leucine into the polypeptides of peripheral nerve myelin indicate that both in control and diabetic animals, various polypeptides have different metabolic activity. It appears from the in vitro findings that the major component (mol wet 28,000 ) is metabolically inactive compared to other components and may represent a "structural" membrane (myelin) protein. In contrast, the higher molecular weight group of polypeptides is the most active, and in terms of relative specific activity, their metabolic activity is the most severely affected by insulin deficiency.

Whether or not these findings reflect an effect of insulin on the synthesis of myelin components or on the transport of labeled precursor across the cell membrane, they do provide strong evidence that the cell synthesizing myelin in peripheral nerve is affected by insulin. Because myelin is an extension of the Schwann cell plasma membrane, it is most likely synthesized by

\footnotetext{
${ }^{2}$ Manuscript in preparation.
} 
that cell, and therefore, it can be concluded from these studies that this cell is affected by insulin.

The applicability of this finding to the peripheral nerve disease in human diabetes remains uncertain. Although both in human and experimental diabetes abnormality of Schwann cell function has been suggested, questions remain as to the similarity of lesion produced in the two states. These findings do, however, suggest that insulin plays a role in myelin synthesis or maintenance and that insulin-deficient states may be associated with impairment of such a function. It is also likely that the defect in the metabolism of myelin shown in this study reflects a more widespread abnormality in metabolism of the plasma membrane in other cells in insulin-deficient states.

\section{ACKNOWLEDGMENTS}

The expert technical assistance of $\mathrm{Mr}$. Charles Hapcook and Mr. Ira Silberlicht is appreciated.

This study was supported in part by the Veterans Administration and by U. S. Public Health Service Grant (NS-10763).

\section{REFERENCES}

1. Spritz, N., B. Geyer, and H. Singh. 1973. Peripheral nerve myelin in experimental diabetes. J. Clin. Invest. 52: $80 a$. (Abstr.)

2. Eliasson, S. G. 1966. Lipid synthesis in peripheral nerve from alloxan diabetic rats. Lipids. 1 : 237-240.

3. Field, R. A., and L. C. Adams. 1965. Insulin response of peripheral nerve: II. Effects on lipid metabolism. Biochim. Biophys. Acta. 106: 474-479.

4. Pratt, J. H., J. F. Berry, B. Kaye, and F. C. Goetz. 1969. Lipid class and fatty acid composition of rat brain and sciatic nerve in alloxan diabetes. Diabetes. 18: 556561.
5. Field, R. A., and L. C. Adams. 1964. Insulin response of peripheral nerve. I. Effects on glucose metabolism and permeability. Medicine (Baltimore). 43: 275-279.

6. Shichiri, M. 1963. Biochemical studies of peripheral nerves in alloxan diabetic animals. I. ${ }^{14} \mathrm{C}$-incorporation into lipid and ${ }^{14} \mathrm{CO}_{2}$-production from ${ }^{14} \mathrm{C}$-labelled precursors. Med. J. Osaka Univ. 13: 305-312.

7. Rawlins, F. A., and M. E. Smith. 1971. Myelin synthesis in vitro: a comparative study of central and peripheral nervous tissue. J. Neurochem. 18: 1861-1870.

8. Autilio, L. A., W. T. Norton, and R. D. Terry. 1964. The preparation and some properties of purified myelin from the central nervous system. J. Neurochem. 11: 11-27.

9. Singh, H., N. Spritz, and B. Geyer. 1971. Studies of brain myelin in the "quaking mouse." J. Lipid Res. 12 : $473-481$.

10. Spritz, N., H. Singh, and B. Geyer. 1973. Myelin from human peripheral nerves. Quantitative and qualitative studies in two age groups. J. Clin. Invest. 52: 520-523.

11. Korn, E. D. 1969. Cell membranes: structure and function. Annu. Rev. Biochem. 38: 263-288.

12. Folch, J., M. Lees, and G. H. Sloane Stanley. 1957. A simple method for the isolation and purification of total lipides from animal tissues. J. Biol. Chem. 226: 497-509.

13. Rouser, G., G. Kritchevsky, and A. Yamamoto. 1967. Column chromatographic and associated procedure for separation and determination of phosphatides and glycolipid. In Lipid Chromatographic Analysis. G. V. Marinetti, editor. Marcel Dekker, Inc., New York. 1: 99-162.

14. Bartlett, G. R. 1959. Phosphorus assay in column chromatography. J. Biol. Chem. 234: 466-468.

15. Guinn, G. 1967. An ultrasensitive chemical test for quantitative chromatography of sugars. J. Chromatogr. 30 : 178-182

16. Lowry, O. H., N. J. Rosebrough, A. L. Farr, and R. J. Randall. 1951. Protein measurement with the Folin phenol reagent. J. Biol. Chem. 193: 265-275.

17. Singh, H., and N. Spritz. 1974. Polypeptide components of myelin from rat peripheral nerve. Biochim. Biophys. Acta. 351: 379-386. 